\title{
Identification of Celecoxib-Targeted Proteins Using Label-Free Thermal Proteome Profiling on Rat Hippocampus ${ }^{\text {s }}$
}

\author{
Elham Gholizadeh, ㅈezeza Karbalaei, Ali Khaleghian, Mona Salimi, Kambiz Gilany, \\ Rabah Soliymani, Ziaurrehman Tanoli, Hassan Rezadoost, Marc Baumann, \\ 이 Mohieddin Jafari, and 기고 Tang
}

Department of Biochemistry, Faculty of Medicine, Semnan University of Medical Sciences, Semnan, Iran (E.G., A.K.);Department of Psychology, College of Science and Technology, Temple University, Philadelphia, Pennsylvania (R.K.); Physiology and Pharmacology Department, Pasteur Institute of Iran, Tehran, Iran (M.S.); Reproductive Immunology Research Center, Avicenna Research Institute, and Integrative Oncology Department, Breast Cancer Research Center, Motamed Cancer Institute, ACECR, Tehran, Iran (K.G.); Medicum, Biochemistry/Developmental Biology and HiLIFE, Meilahti Clinical Proteomics Core Facility (R.S., M.B.), and Research Program in Systems Oncology, Faculty of Medicine (Z.T., M.J., J.T.), University of Helsinki, Helsinki, Finland; and Medicinal Plants and Drugs Research Institute, Shahid Beheshti University, Tehran, Iran (H.R.)

Received December 3, 2020; accepted February 10, 2021

\begin{abstract}
Celecoxib, or Celebrex, a nonsteroidal anti-inflammatory drug, is one of the most common medicines for treating inflammatory diseases. Recently, it has been shown that celecoxib is associated with implications in complex diseases, such as Alzheimer disease and cancer as well as with cardiovascular risk assessment and toxicity, suggesting that celecoxib may affect multiple unknown targets. In this project, we detected targets of celecoxib within the nervous system using a label-free thermal proteome profiling method. First, proteins of the rat hippocampus were treated with multiple drug concentrations and temperatures. Next, we separated the soluble proteins from the denatured and sedimented total protein load by ultracentrifugation. Subsequently, the soluble proteins were analyzed by nano-liquid chromatography tandem mass spectrometry to determine the identity of the celecoxib-targeted proteins based on structural changes by thermal stability variation of targeted proteins toward higher solubility in the higher temperatures. In the analysis of the soluble protein extract at $67^{\circ} \mathrm{C}, 44$ proteins were uniquely detected in drug-treated samples out of all 478 identified proteins at this temperature. Ras-associated binding
\end{abstract}

protein $4 \mathrm{a}, 1$ out of these 44 proteins, has previously been reported as one of the celecoxib off targets in the rat central nervous system. Furthermore, we provide more molecular details through biomedical enrichment analysis to explore the potential role of all detected proteins in the biologic systems. We show that the determined proteins play a role in the signaling pathways related to neurodegenerative disease-and cancer pathways. Finally, we fill out molecular supporting evidence for using celecoxib toward the drug-repurposing approach by exploring drug targets.

\section{SIGNIFICANCE STATEMENT}

This study determined 44 off-target proteins of celecoxib, a nonsteroidal anti-inflammatory and one of the most common medicines for treating inflammatory diseases. It shows that these proteins play a role in the signaling pathways related to neurodegenerative disease and cancer pathways. Finally, the study provides molecular supporting evidence for using celecoxib toward the drug-repurposing approach by exploring drug targets.

\section{Introduction}

Celecoxib is a nonsteroidal anti-inflammatory drug (NSAID) with anti-inflammatory, analgesic, and antipyretic properties.

This study was financially supported by the National Institute for Medical Research Development of Iran (NIMAD) as Elite Grants [Grant 964580], Academy of Finland [Grant 317680] and [Grant 332454], and European Research Council [Grant 716063].

The authors declare that there is no conflict of interest.

https://doi.org/10.1124/molpharm.120.000210.

[S This article has supplemental material available at molpharm.aspetjournals. org.

ABBREVIATIONS: BP, biologic process; CC, cellular component; CETSA, cellular thermal shift assay; CNS, central nervous system; COX, cyclooxygenase; DB, Drug Bank; DTC, Drug Target Commons; ER, endoplasmic reticulum; GO, gene ontology; HSP, heat shock protein; LC, liquid chromatography; MF, molecular function; MGI, Mouse Genome Informatics; MS, mass spectrometry; MS/MS, tandem MS; NSAID, nonsteroidal anti-inflammatory drug; PDP, Probes \& Drugs portal; PTM, post-translational modification; Rab, Ras-associated binding protein; SERCA, sarcoplasmic/ER Ca2+-ATPase; SRP, signal-recognition particle; ST, Super Target; TPP, thermal proteome profiling. 
isoforms with a predominant effect on COX-1 (Smith et al., 2000). Most NSAIDs have broad side effects, such as bleeding, ulceration, and perforation on gastrointestinal tract, whereas celecoxib selectively inhibits COX-2 and does not have side effects on the digestive system (Rahme et al., 2007; Atukorala and Hunter, 2013). Since celecoxib suppresses pain and inflammation, it is one of the most commonly prescribed drugs and accounts for 5\%-10\% of prescriptions per year (Jones, 2001; Onder et al., 2004; Wongrakpanich et al., 2018). Celecoxib can easily access the central nervous system (CNS), whereas the mechanism of action through its protein targets in CNS has not yet been fully elucidated (Fond et al., 2014).

Determining the affinity of a drug for all its potential targets is the main challenge for understanding the mechanism of action in pharmaceutical sciences. Target-based drug discovery starts by identifying molecular targets, which are supposed to have an essential role in the disease of interest (Sams-Dodd, 2005; Schmidt, 2010; Schenone et al., 2013), opposed to phenotypic-based drug discovery. The mechanism of drug performance, which is essential for designing a drug, is not often considered in phenotypic-based drug discovery investigations (Swinney, 2013). However, target-based drug discovery research also has its limitations; for example, proving the presence of a protein target in a particular biologic pathway or its involvement in disease is a time- and costconsuming process. Therefore, the development of alternative strategies for target deconvolution is on-demand. Different strategies have emerged, which are based on changes in target stability upon compound binding (Sjostrom et al., 2015; Li et al., 2016). Some successful options are stability of proteins from rates of oxidation (West et al., 2008; West et al., 2010; Strickland et al., 2013), drug affinity responsive target stability (Lomenick et al., 2011), cellular thermal shift assay (CETSA) (Martinez Molina et al., 2013), and thermal proteome profiling (TPP) (Savitski et al., 2014). In stability of proteins from rates of oxidation, proteins are subjected to an increasing concentration of a chemical denaturant (hydrogen peroxide) and then the evaluation of oxidized methionine in unfolded proteins. The folding free energy is then calculated based on the denaturant concentration in the presence and absence of ligands to evaluate protein-ligand affinities. Drug affinity responsive target stability is based on the modification- or immobilization-free limited proteolysis after the binding of a ligand to proteins. This is in accordance with the assumption that protein targets become less susceptible to proteolysis when it is drug-bound and not drug-free, especially the exposed part of the protein, which is protected from protease. In CETSA, changes in the thermal stability of proteins are used for studying the ligand-binding process. However, CETSA can only detect a small number of protein changes since it is limited to an antibody readout. However, the CETSA principles can be combined with mass spectrometry-based proteomics to provide an unbiased identification of more comprehensive drug-protein interactions in a single experiment (Larance and Lamond, 2015; Aebersold and Mann, 2016). TPP, a recently suggested method, can be done in high throughput to identify drug targets (Reckzeh et al., 2019). It can also be applied in living cells in addition to in vitro studies without requiring compound labeling. It is an approach that combines CETSA and quantitative mass spectrometry, enabling monitoring of changes in protein thermal stability across heat scaling up. Identifying drug targets in TPP is based on changes in the thermal stability of proteins after their binding to the substrates (i.e., drugs) (Pace and McGrath, 1980; Vedadi et al., 2006). This stability is mostly related to the protein melting temperature, a temperature at which the process of unfolding will happen (Jarzab et al., 2020).

Thermal stress usually causes some irreversible changes in the structure of a protein leading to unfolding. This process leads to the exposure of the hidden hydrophobic core of a protein and, finally, to its aggregation (Kurganov et al., 2002; Asial et al., 2013). For proteins connected to a ligand (e.g., a drug), more energy is needed for unfolding because the dissociation of a ligand from the protein requires some energy itself (Pace and McGrath, 1980). In other words, binding of a ligand to a protein causes the formation of a complex with increased stability compared with the free protein. Therefore, these proteins are more resistant to the process of unfolding induced by heat, a fact that is the basis of TPP (Savitski et al., 2014; Franken et al., 2015; Reinhard et al., 2015; Becher et al., 2016). TPP can be used to investigate any change in the structure of the protein (Franken et al., 2015). TPP is unique in having the following advantages: Although it does not require any labeling, it can be applied to living cells, and it permits an objective search of drug targets (Mateus et al., 2017).

In the present study we have investigated targets of celecoxib, a high-prevalence drug, using a label-free TPP method in rat hippocampus. We also provide supporting computational evidence related to biologic annotations of the targets to explain the potential repurposing implications of this NSAID (Zagidullin et al., 2019; Tanoli et al., 2020). We further show that several proteins related to cancer and inflammation pathways are the targets of celecoxib. The results of these experiments are also compared with the available knowledge across all drug-target interaction databases. In addition to reinforcing previous findings, we especially explore more potential off targets of celecoxib within the nervous system. Based on these results, we suggest a conceivable repurposing strategy of this drug for neuronal inflammation as well as cancer.

\section{Materials and Methods}

Preparation Rat Brain for Protein Extraction. Five rats were used as biologic replicates to not affect the present study by two crucial variables (i.e., sex and weight). Therefore, five male rats of Rattus norvegicus were prepared by the weight of $200 \pm 10$ g. After dissecting the hippocampus under complete anesthesia, tissue was washed two times with cold PBS. Experiments were approved by the local Animal Ethics Committee (National Institute for Medical Research Development Ethics Board, National Institute for Medical Research Development of Iran, 964580). Immediately after washing, the hippocampus was homogenized and lysed in RIPA buffer ( $\mathrm{NaCl}$, Triton 500, Na deoxycholate, Tris HCl, Protease Inhibitor Cocktail $\mathrm{pH}$ 7.4). Then, the homogenates were centrifuged at $20,000 \mathrm{~g}$ for 20 minutes at $4^{\circ} \mathrm{C}$ to separate the protein extracts from precipitates (Pei et al., 2007). Bradford assay was used to measure protein concentrations.

Drug Treatment and Heating Procedure. A solution of celecoxib in DMSO was added to the protein extracts to have a $0.1 \%$ finalDMSO concentration. In this study, five concentrations of celecoxib including $20,10,5,1$, and $0.1 \mu \mathrm{M}$ were used, based on the pharmaceutical 
implications as described previously (Paulson et al., 2001; Dembo et al., 2005; Kang et al., 2009; Wang et al., 2017). Two negative controls (i.e., control with DMSO and control with pure double distilled water) were also used. The starting protein amounts in each tube were $1600 \mu \mathrm{g}$ in total of $400 \mu \mathrm{l}$ solution. The extracts were incubated for 10 minutes at $23^{\circ} \mathrm{C}$ and then divided into 4 aliquots of $100 \mu l$.

These 4 aliquots were heated for 3 minutes at the following temperatures: $37^{\circ} \mathrm{C}, 47^{\circ} \mathrm{C}, 57^{\circ} \mathrm{C}$, and $67^{\circ} \mathrm{C}$. This was followed by cooling down at room temperature for 3 minutes. Subsequently, the extracts were centrifuged at $60,000 \mathrm{~g}$ for 30 minutes at $4^{\circ} \mathrm{C}$, and finally, the supernatant that contained soluble targeted proteins was collected and stored at $-20^{\circ} \mathrm{C}$ for further investigations as previously described (Jafari et al., 2014; Savitski et al., 2014).

Sample Preparation, Proteolytic Digestion, and Nano-Liquid Chromatography-Electrospray Ionization-Tandem Mass Spectrometry. Next, the extracted proteins treated with the highest drug concentration (i.e., $20 \mu \mathrm{M}$ at the highest temperature, $67^{\circ} \mathrm{C}$ ) were selected for the protein identification step. The highest dosage of celecoxib and the highest temperature were used to avoid detection of the weak or transient interactions of celecoxib and the proteins. The same temperature was used to analyze and identify proteins in the control negative samples.

The protein samples were digested in Amicon Ultra- 0.5 centrifugal filters using a modified filter-aided sample preparation method (Wiśniewski et al., 2009; Scifo et al., 2015). In brief, reduction and alkylation of samples were performed by the addition of tris $(2$ carboxyethyl)phosphine and iodoacetamide to final concentrations of 2 and $50 \mathrm{mM}$, respectively, and this was followed by incubation in the dark for 30 minutes. The trypsin solution was added in a ratio of 1:50 $\mathrm{w} / \mathrm{w}$ in $50 \mathrm{mM}$ ammonium bicarbonate and incubated overnight at room temperature. The peptide samples were cleaned using C18reverse-phase ZipTipTM (Millipore). Dried peptide digest was resuspended in $1 \%$ trifluoroacetic acid and sonicated in a water bath for 1 minute before injection. Fractionated protein digests were analyzed in nano-LC-Thermo Q Exactive Plus Orbi-Trap MS. Each sample run was followed by two empty runs to wash out any remaining peptides from previous runs. The peptides were separated by Easy-nLC system (Thermo Scientific) equipped with a reverse-phase trapping column Acclaim PepMapTM 100 (C18, $75 \mu \mathrm{m} \times 20 \mathrm{~mm}, 3-\mu \mathrm{m}$ particles, $100 \AA$; Thermo Scientific), and this was followed by an analytical Acclaim PepMapTM 100 RSLC reversed-phase column $(\mathrm{C} 18,75 \mu \mathrm{m} \times 250 \mathrm{~mm}$, $2-\mu \mathrm{m}$ particles, $100 \AA$; Thermo Scientific). The injected sample analytes were trapped at a flow rate of $2 \mu \mathrm{l} /$ minute in $100 \%$ of solution $\mathrm{A}(0.1 \%$ formic acid $)$. After trapping, the peptides were separated with a linear gradient of 120 minutes comprising 96 minutes from $3 \%$ to $30 \%$ of solution B ( $0.1 \%$ formic acid/ $80 \%$ acetonitrile), 7 minutes from $30 \%$ to $40 \%$ of solution B, and 4 minutes from $40 \%$ to $95 \%$ of solution B.

LC-MS data acquisition was done with the mass spectrometer settings as follows: The resolution was set to 140,000 for MS scans and 17,500 for the MS/MS scans. Full MS was acquired from 350 to $1400 \mathrm{~m} / \mathrm{z}$, and the 10 most abundant precursor ions were selected for fragmentation with 30 seconds dynamic exclusion time. Ions with $2+$, $3+$, and 4+ charge were selected for MS/MS analysis. Secondary ions were isolated with a window of $1.2 \mathrm{~m} / \mathrm{z}$. The MS automatic gain control target was set to $3 \times 106$ counts, whereas the MS/MS automatic gain control target was set to $1 \times 105$. Dynamic exclusion was set with a duration of 20 seconds. The Normalized Collision Energy stepped was set to $28 \mathrm{~kJ} \mathrm{~mol}^{-1}$.

Proteomic Data and Bioinformatic Analysis. After LC-MS/ MS acquisition, the raw files were qualitatively analyzed by Proteome Discoverer, version 2.4.0.305 (Thermo Scientific). The identification of proteins by Proteome Discoverer was performed against the UniProt Rat protein database (release 11-2019 with 8086 entries) using the built-in SEQUEST HT engine. The following parameters were used: $10 \mathrm{ppm}$ and $0.25 \mathrm{Da}$ were the tolerance values set for MS and MS/MS, respectively. Trypsin was used as the digesting enzyme, and two missed cleavages were allowed. The carbamidomethylation of cysteines was set as a fixed modification, whereas the oxidation of methionine and deamidation of asparagine and glutamine were set as variable modifications. The false discovery rate was set to less than 0.01 , and a minimum length of six amino acids (one peptide per protein) was required for each peptide hit.

After the identification of proteins, for better understanding of the role and importance of proteins, enrichment analysis was used to determine the corresponding biologic processes (BPs) by EnrichR (Chen et al., 2013). Eight different libraries were selected to explore biomedical annotations of drug targets, including gene ontology (GO), molecular function (MF), GO cellular component (CC), GO BP, DisGeNet (Piñero et al., 2017), HumanPhen (Köhler et al., 2019), Mouse Genome Informatics (MGI) (Eppig et al., 2017), PheWeb (Gagliano Taliun et al., 2020), and WikiPathways (Kutmon et al., 2016). We used EnrichR's combined scores and adjusted $P$ values to sort annotations in descending fashion. Also, Post-translational modification Enrichment, Integration and Matching ANalysis (PEIMAN) software was used to determine possible enriched post-translational modifications (PTMs) in the list of protein targets (Nickchi et al., 2015).

Statistical Analysis. All data were analyzed using R (version 4.0.3) with RStudio (Free Software Foundation Inc., Boston, MA). Unless otherwise noted, data are showed as mean \pm S.D. for technical replicates. Statistical significance was calculated by Fisher's exact test and hypergeometric test for enrichment analysis. Multiple testing corrections were done using the Benjamini-Hochberg method (Jafari and Ansari-Pour, 2019). Using the decoy database search feature, the q-value for protein identification was calculated in Proteome Discoverer software. Because of the exploratory nature of this study, we reduced biologic variability by pooling the rat samples and focused on the physicochemical effect of celecoxib treatment on extracted proteins from the rat hippocampus. Hence, testing a null hypothesis among rats is irrelevant, and the statistical tests' outcomes are interpretable based on technical replicates in each step of our study.

\section{Results}

The amount of soluble proteins significantly decreased with increasing temperature (Supplemental File 1). The declining pattern was observed for all five drug concentrations: 20, 10, 5, 1 , and $0.1 \mu \mathrm{M}$ as well as two negative controls (i.e., water and DMSO). Finally, the protein sample treated in $20-\mu \mathrm{M}$ drug concentration and $67^{\circ} \mathrm{C}$ was chosen for further analysis. In fact, proteins start unfolding at high temperature unless the binding energy of any binding partner, such as a drug, is high enough (Petsko and Ringe, 2004; Guo et al., 2012). We used the highest temperature to avoid detecting the weak and transient interactions among celecoxib and the proteins. Also, we selected the highest dosage of celecoxib to detect all potent drug-target interactions.

A comprehensive comparison of identified proteins in samples treated with celecoxib and two controls is shown in Fig. 1 and Fig. 2A. These proteins were soluble at $67^{\circ} \mathrm{C}$ after the treatment in $20-\mu \mathrm{M}$ celecoxib, water, and DMSO, respectively, and finally detected by nano-LC-Thermo Q Exactive Plus Orbi-Trap MS. Water control treatment contained only protein samples without any other additional substances, and 351 proteins were detected in this subset. Also, 378 proteins were identified in the DMSO treatment (other negative control). Furthermore, 357 proteins were detected in the drug-treated sample, in which 44 proteins were specific to this subset (Supplemental File 2). Fifteen out of all identified proteins were heat shock proteins (HSPs), which indicates the intrinsic structural stability of these proteins 


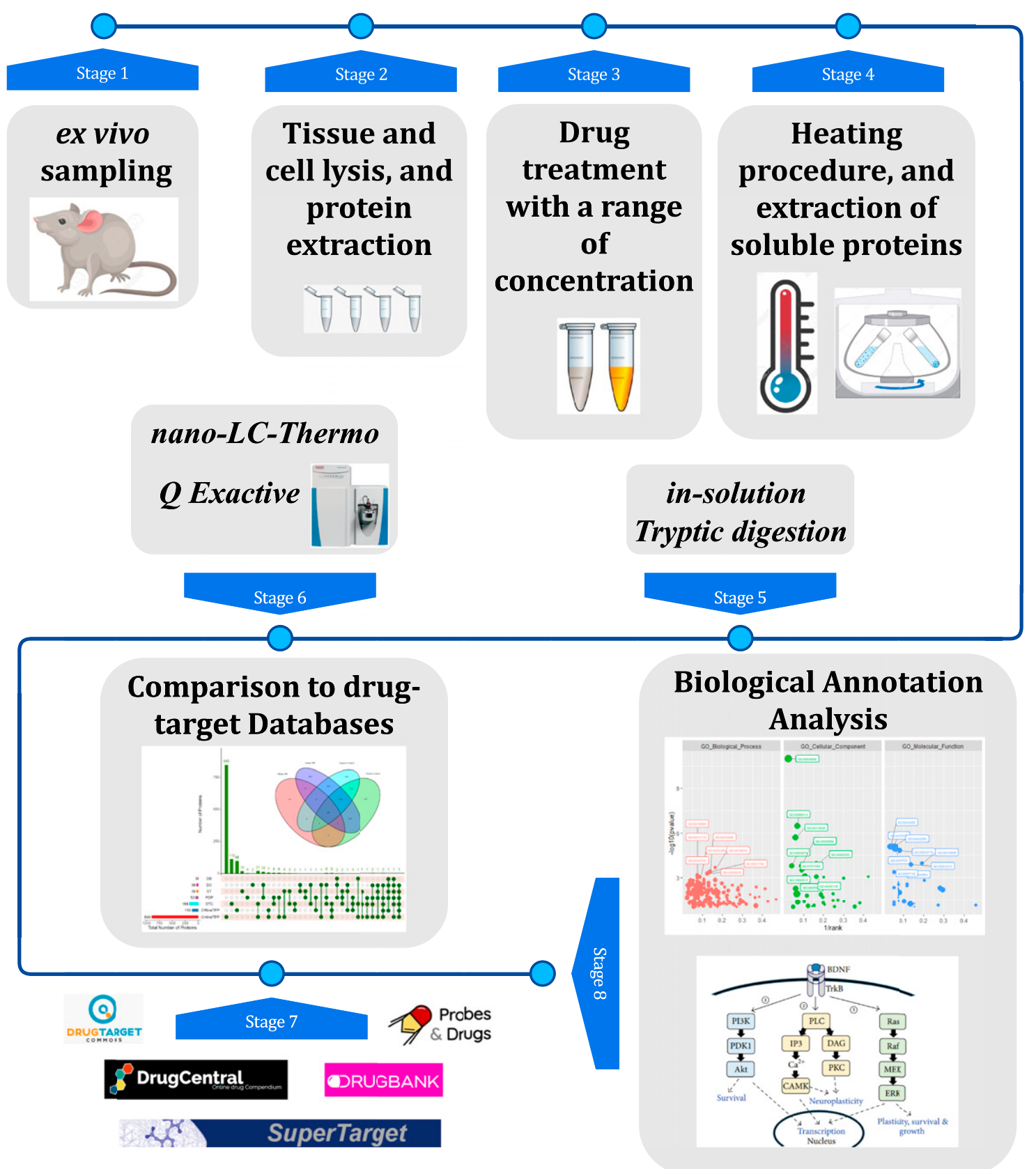

Fig. 1. Schematic representation of TPP-based drug target discovery using samples of rat hippocampus. Then, we extracted proteins from the hippocampus after tissue homogenization and cell lysis. Next, the samples were treated with a range of compound concentrations. Each concentration was treated with four serial temperatures (i.e., $37^{\circ} \mathrm{C}, 47^{\circ} \mathrm{C}, 57^{\circ} \mathrm{C}, 67^{\circ} \mathrm{C}$ ). Then, soluble proteins were separated and tryptic-digested before mass spectrometry. Protein identification was done using nano-LC-electrospray ionization-Thermo Q Exactive Plus Orbi-Trap MS followed by Proteome Discoverer software. Finally, data processing and computational analysis were performed to compare with previously identified celecoxib targets in different databases and to explore the possible enriched biologic annotations in the identified protein targets.

across the high temperature (Usman et al., 2014). The identified HSPs were shared with other groups, such as HSP $90-\beta$ and $60-\mathrm{kDa}$ mitochondrial heat shock protein. Thus, we could infer that HSPs are not the particular target of celecoxib.

We also examined the previously known targets of celecoxib according to five drug-target databases for all species (Fig. 2B), including $R$. norvegicus (rat) in particular (Fig. 2C). Then, we compared the TPP-identified proteins with the known targets of this drug in rats. Out of 242 already-identified celecoxib targets for 24 species in all five databases, only 21 proteins were found in rat. Figure 2, $\mathrm{B}$ and $\mathrm{C}$ show the total number of proteins in each set by the horizontal bar plots. The vertical bar plot indicates the number of proteins in each database uniquely and the different set of the intersections sorted by the frequency of targets. In this analysis, we selected five well known drug-target databases [i.e., Drug Bank (DB) (Wishart et al., 2018), Super Target (ST) (Hecker et al., 2012), Probes \& Drugs portal (PDP) (Skuta et al., 2017), Chembl (Bento et al., 2014), and Drug Target Commons (DTC)] (Tang et al., 2018; Tanoli et al., 2018). The DB database shows five targets for celecoxib, of which one was related to the rat. The ST and PDP databases suggest 41 and 45 proteins as targets of celecoxib, of 
A
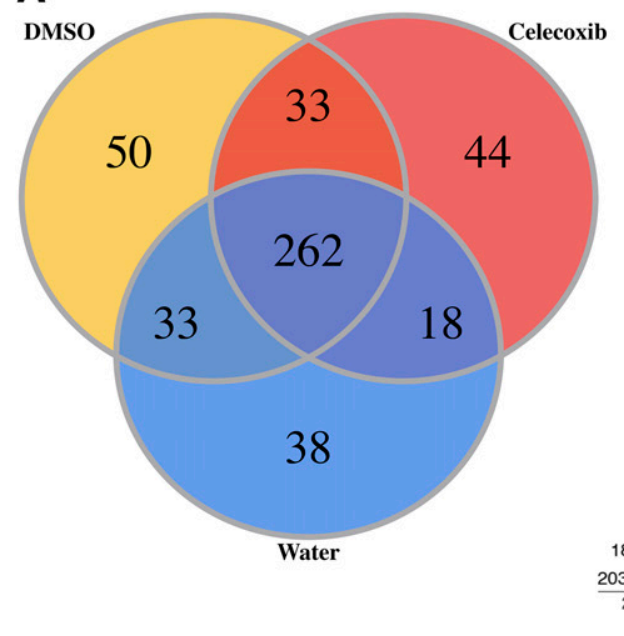

C

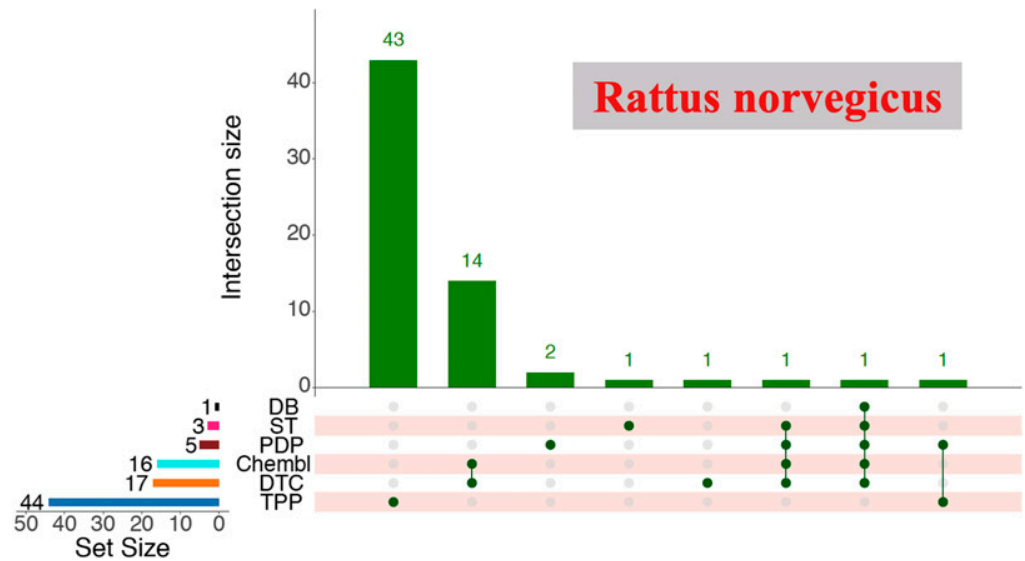

B
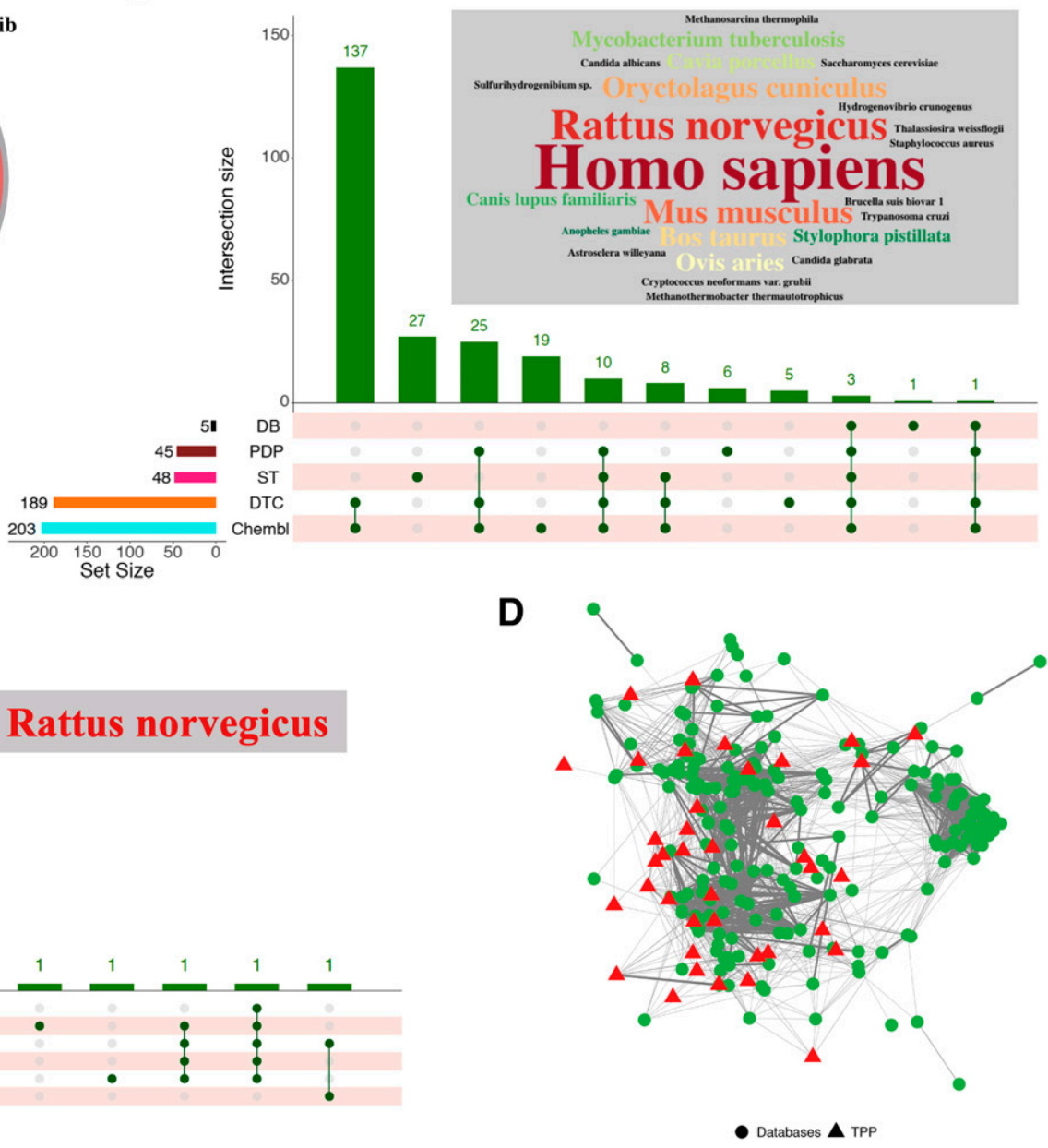

Fig. 2. (A) The Venn diagram of identified proteins of rat hippocampus proteome recovered by TPP technique in three groups: treated with DMSO, $\mathrm{H}_{2} \mathrm{O}$, and celecoxib $(20 \mu \mathrm{M})$. (B) Drug-target database comparison based on celecoxib-targeted proteins within diverse species. In this inset plot, intersections between the databases are illustrated. The horizontal bar plot shows the total number of proteins in each database. The vertical bar plot indicates the number of proteins in each database uniquely and the different sets of the intersections. DB, ST, Drug Central (DC), PDP, and DTC are represented in this plot. The inset plot displays the characterized species in the mentioned databases. We scaled the word size by their frequency of corresponding protein targets of celecoxib in each species independently. (C) Rat-specific drug-target database comparison based on celecoxib-targeted proteins along with the TPP-identified proteins. (D) Homology network of TPP-identified proteins and reported targets of celecoxib in drug-target databases. The identified proteins in the present study are shown with a red triangle, and the proteins introduced by the databases are displayed with green circles. The thickness of the edges indicates the identity percentage of protein sequences in this study.

which three and five are expressed in the rat, respectively. Searching in DTC and Chembl databases introduced 168 and 203 proteins in 24 species as celecoxib targets, and 17 and 16 of them are specified in the rat, respectively. In total, around $70 \%$ of the identified targets are related to human proteins, and the proportion of rat-specific proteins is much lower, especially if we consider each database independently. It implies the lack of complete information in rat species databases, avoiding a more comprehensive celecoxib target profile in rats. It should be considered that most of the introduced protein targets are associated with the COX protein family and are involved in NSAID-related pathways like the inflammatory process, which is the explicit indication of this drug.

As shown in Fig. 2B, the intersection of all databases contains only two human proteins (i.e., 3-phosphoinositide-dependent protein kinase 1 , carbonic anhydrase 2 , and one rat protein, prostaglandin-endoperoxide synthase 2 ) because of the cross reference of the resources. Chembl and DTC are the most comprehensive drug-target bioactivity resources based on manual curation (more than 1.9 million chemicals and 13,000 protein targets); therefore, it was expected that they have the highest number of intersected proteins for celecoxib. At the same time, the other databases used experimental evidence to explore targets of drugs. Only six proteins have been identified as celecoxib targets using ST, DB, and PDP so far. On the other hand, the main subject of celecoxib studies is to study the effects of this drug on the heart and circulatory system; hence, researchers focused on exploring new off targets on related organs and tissues. Although celecoxib can simply pass through the blood-brain barrier, its impacts on the brain and CNS have not been well described. Here, we focused on a minute part of CNS (i.e., the hippocampus); hence, we did not anticipate to observe a high proportion of intersected protein targets with the other databases. However, we found a Ras-associated binding protein (Rab)$2 \mathrm{~A}$ to be a shared celecoxib-targeted protein between TPPidentified proteins and the PDP database. The high amount 
of expression of Rab-2A in the whole brain has been previously reported (Palasca et al., 2018), which was helpful for our study (Fig. 2; Supplemental File 3). This protein can be a clue to explain the association of celecoxib with cancerrelated pathways since Rab-2A is a cancer driver gene product, and it plays a role in promoting tumorigenesis (Luo et al., 2015).

We also investigated the homology of TPP-identified proteins with reported celecoxib targets to explore structural similarities (Fig. 2D). The overall similarity of amino acid sequences in both protein groups was represented using a protein homology network. In this graph, the thickness of the edges indicates the amino acid identity percentages. There were 665 and 3138 pairwise similarities with more than $25 \%$ and $10 \%$ thresholds. Thus, it can be concluded that several of TPP-identified proteins have a close homology with the previously reported celecoxib-targeted proteins.

Furthermore, to characterize the related biologic functions of the TPP-identified proteins, we implemented geneenrichment analysis using disease- and pathway-related resources available in EnrichR (Fig. 3). The enriched annotations in DisGeNet database include muscular stiffness with the lowest adjusted $P$ value. Neurodegenerative diseases, such as Alzheimer disease and epilepsy, and breast cancer-related annotations are also highly enriched in these proteins. Therefore, it can be a clue for celecoxib to be a potential choice for add-on therapy in these diseases. We also assessed other resources, such as MGI, HumanPhen, and PheWeb, for exploring enriched phenotypic annotations in the TPP-identified list of 44 proteins. In these databases, terms such as "Broad head," "increased motor neuron number," "Schizophrenia," "psychotic disorders," "acquired hemolytic anemias," and "abnormal thrombopoiesis" showed the lowest adjusted $P$ values. In the perspective of pathway enrichment analysis, mRNA processing, such as cytoplasmic ribosomal proteins and splicing factor Nova, regulated synaptic proteins, which were also enriched along with cancer-related pathways, such as interleukin-3, PI3K-Akt-mTOR, and G protein-mediated signaling pathways, which have an importance in cancer, inflammation, and neurodegenerative diseases.

In Fig. 4 and Supplemental File 4, the enriched gene ontology annotations (i.e., BPs, CCs, and MFs) were summarized by using semantic similarity. The annotations of $\mathrm{BP}$ were divided into six major subsets (; Supplemental File 4A). The signal-recognition particle (SRP)-dependent cotranslational protein targeting to membrane processes contributes to the prominent concept in this analysis. This process is responsible

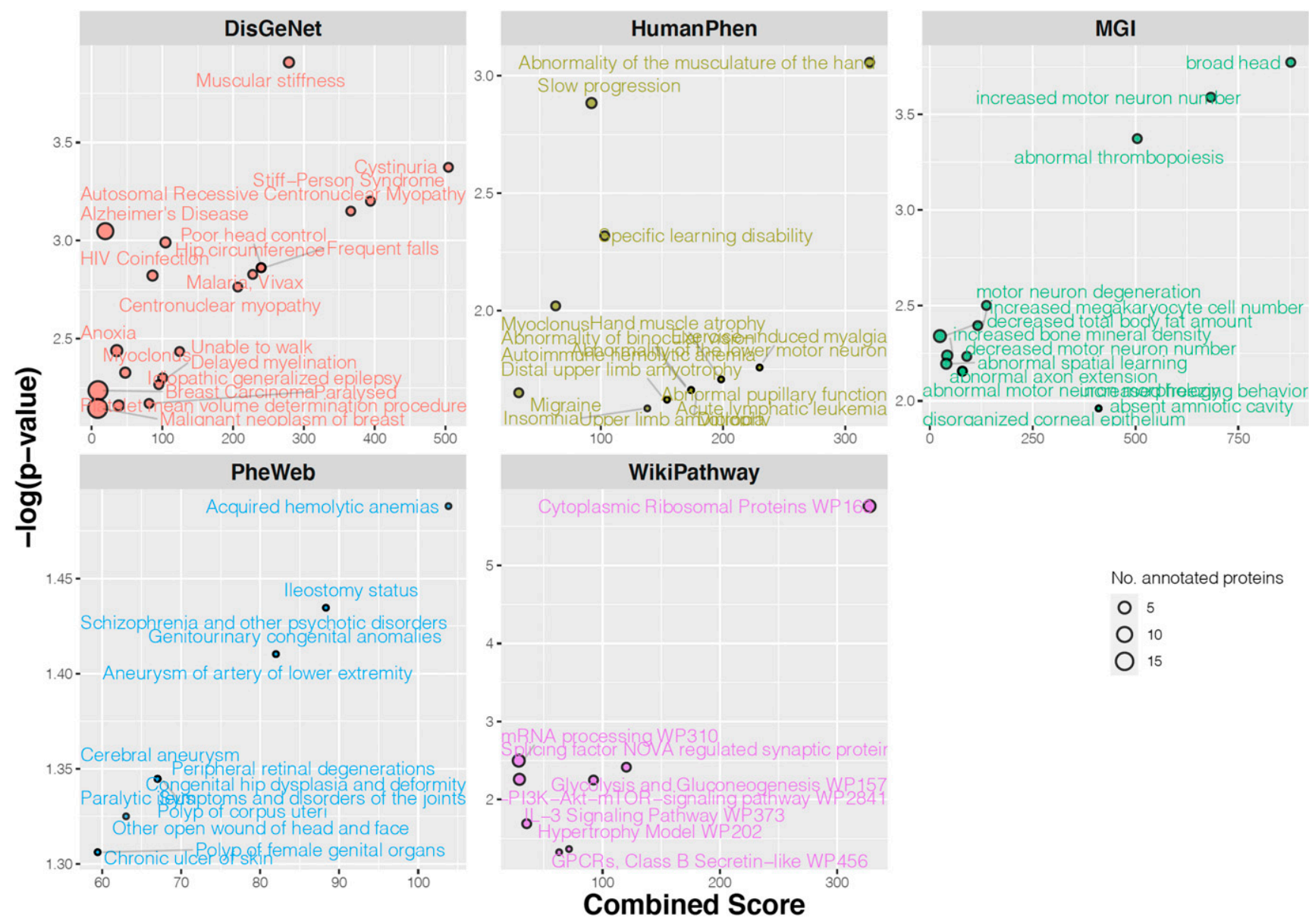

Fig. 3. Enrichment analysis of TPP-identified proteins as the targets of celecoxib in the rat hippocampus. This plot indicates enriched annotations related to disease, phenotypes, and biologic pathways of celecoxib-targeted proteins. Each panel distinctly represents the annotations of gene-disease associations (DisGeNET), Human Phenotype Ontology (HumanPhen), MGI, UKBiobank PheWeb, and WikiPathway. These annotations are displayed with the negative of logarithmic $P$ values of Fisher's exact test and combined scores based on EnrichR webtool. GPCR, G protein-coupled receptor; HIV, human immunodeficiency virus; PI3K-Akt-mTOR, phosphatidylinositol 3-kinase-protein kinase B-mammalian target of rapamycin. 


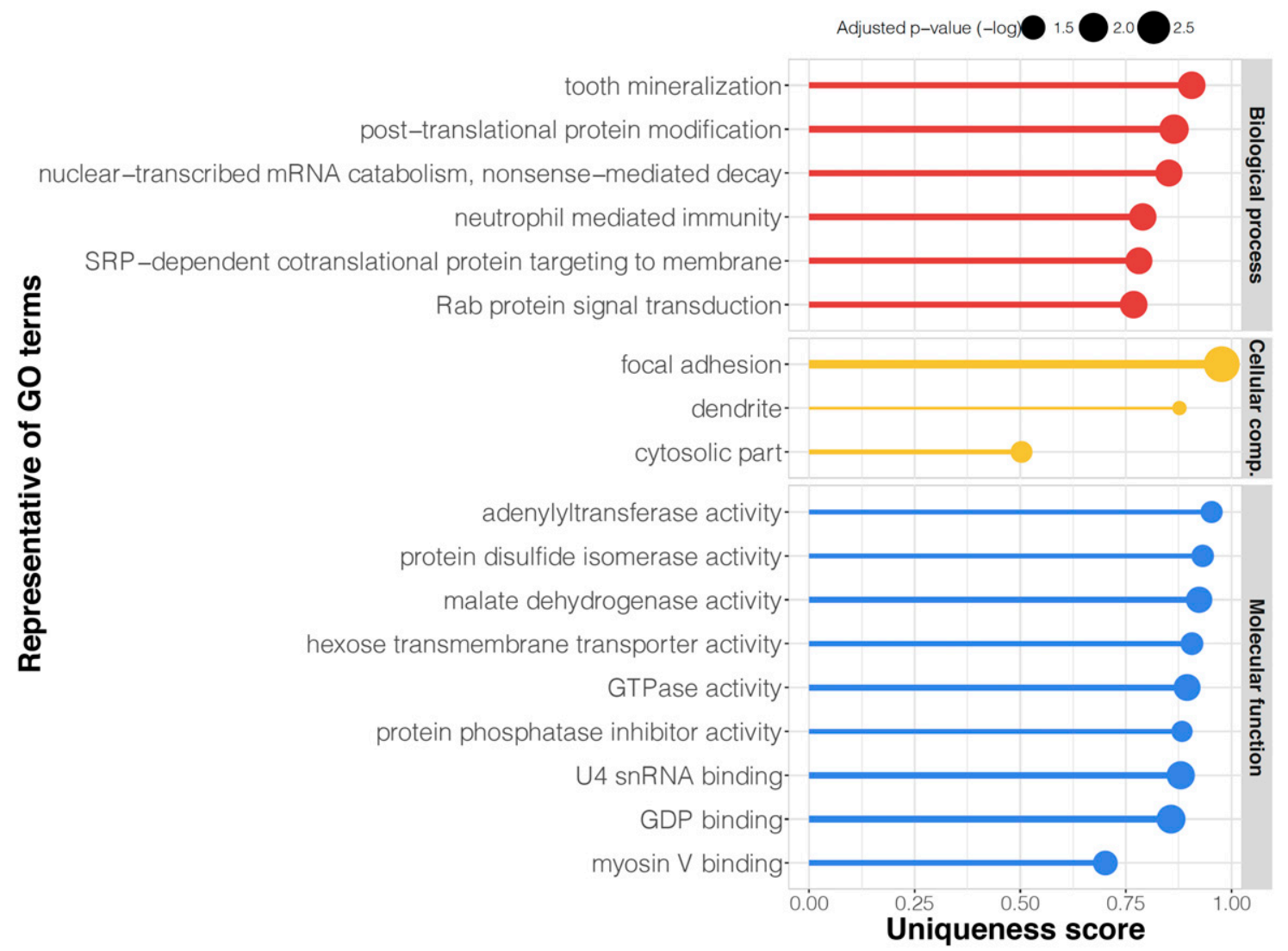

Fig. 4. REVIGO Gene Ontology representative terms for TPP-identified proteins as the targets of celecoxib in the rat hippocampus. Each lollipop plot contains cluster representative terms of enriched annotations based on semantic similarity analysis in REVIGO. The loosely related annotations are joined together and visualized by the avg. of uniqueness scores calculated based on semantic similarity of the GO annotations in the biologic process, cellular component, and molecular function, as more uniqueness is more preferable. The points' sizes were adjusted to reflect the avg. adjusted $P$ values $(-\log 10)$ of Fisher's exact test in the enrichment analysis by EnrichR webtool. snRNA, small nuclear RNA.

for the targeting of proteins to the cell membrane during translation, and it is dependent on two key components: the $\mathrm{SRP}$ and the SRP receptor. Rab protein signal transduction is the second most prevalent annotation in the treemap of BPs. Rab proteins represent the largest branch of the Ras-like small GTPase superfamily, alternating between GTP- and GDP-bound states and releasing a series of molecular signals within the cell. Nuclear-transcribed mRNA catabolism, nonsense-mediated decay, post-translational protein modification, and neutrophil-mediated immunity are four other groups of annotations in BP similar to the result of pathway enrichment analysis. These terms indicate the long-term effects of celecoxib by PTM-related mechanisms and G protein-related signaling pathways. At the molecular level, nine groups of MF annotations were illustrated for TPPidentified proteins (Fig. 4; Supplemental File 4B). The activities related to signal transduction in neuronal cells involving transport mechanisms were also highlighted, such as myosin, actin, and cadherin binding, in addition to GDP binding and GTPase activity. The enriched annotations of CC are mainly corresponding to the cytosolic part, which also underscores altering the signaling pathways (Jafari et al., 2013) (Fig. 4; Supplemental File 4C).

The enriched PTMs in TPP-identified proteins were also evaluated by PEIMAN software. It is presumed that soluble proteins at $67 \mathrm{C}$ might be enriched in any of PTMs to last longer under temperature changes. We observed 15 enriched
PTMs, which emphasizes the role of PTMs in the thermostability of proteins. For example, acetylation, prenylation, and phosphorylation are significantly detected in all TPPidentified proteins. Citrullination was the specific PTM for celecoxib targets that was statistically enriched by adjusted $P$ value 0.0076. All of the enriched PTMs were confirmed by researching the proteomic data using these PTMs as variable modifications in Proteome Discoverer.

\section{Discussion}

Celecoxib is one of the top-selling NSAID medicines in the world . Also, NSAIDs involve $5 \%-10 \%$ of the remedy of all prescriptions per year (Paulson et al., 2001; Onder et al., 2004). There are some reports that show the possible indication of celecoxib with the neurodegenerative diseases associated with inflammatory processes (Akiyama et al., 2000; Hirsch et al., 2003; (Eikelenboom and van Gool, 2004) Eikelenboom and Van Gool, 2004; McGeer and McGeer, 2004; Terzi et al., 2018). Although celecoxib can pass through the blood-brain barrier and access the CNS, reports about side effects of celecoxib (Goncalves et al., 2010; Nam et al., 2015) are related to cardiovascular diseases rather than the nervous system (Fond et al., 2014). In other words, the major molecular footprints of this medicine on CNS are not well described (Fond et al., 2014). Indeed, as we expected, we observed that most of the introduced targets of celecoxib in different 
databases are not related to CNS. Considering the essential role of celecoxib in the treatment of pain and inflammation and its influence on the CNS, our study aimed to characterize protein targets of this drug, especially in the nervous system.

One of the identified celecoxib targets is Rab-2A, which is a GTPase required for protein transport from the endoplasmic reticulum (ER) to the Golgi complex by regulating coat protein-dependent vesicular transport (Gaudet et al., 2011; Haas et al., 2007). This protein was common between TPPidentified targets and the PDP database (Fig. 2C). PDP is a powerful up-to-date web resource that unifies various commercial and public bioactive compound libraries (Skuta et al., 2017). To explore the role of Rab2A in detail, Sugawara et al. (2014) studied the effect of Rab2A knockdown on glucosestimulated insulin secretion and the Golgi intermediate compartment in the corresponding cells. They reported that inactivation of Rab2A mitigated glucose-induced ER stress and inhibited apoptosis induced by ER stress through enlarging of the ER-Golgi intermediate compartment (Sugawara et al., 2014). Therefore, it seems that celecoxib is associated with apoptosis by targeting Rab-2A and implicating ER stress. Providing more evidence through testing celecoxib on the same cells-insulinoma cells-to clarify the celecoxib influence on the ER stress is warranted.

Also, TPP-identified proteins were enriched in pathways related to neurodegenerative disease and cancer. Interestingly, the anticancer activity of celecoxib has been reported in various models of animal tumors, and it is proposed that this drug is beneficial for the prevention and treatment of cancer (Masferrer et al., 2000; Dannenberg and Subbaramaiah, 2003; Koehne and Dubois, 2004). The molecular mechanisms of antitumoral effects of celecoxib have become a challenging issue, since some reports showed that the effect of celecoxib on cancer is apart from COX-2 inhibition, meaning that celecoxib has other targets than COX-2 (Kashfi and Rigas, 2005; Grösch et al., 2006; Schönthal, 2007). Several components as intermediate candidates have been proposed for the anticancer effects of celecoxib, the most common of which is the sarcoplasmic/endoplasmic reticulum Ca2+-ATPase (SERCA) (Johnson et al., 2002; Tanaka et al., 2005; Pyrko et al., 2007). Our CC enrichment analysis also disclosed that the endoplasmic reticulum lumen annotation was statistically enriched in TPP-identified proteins, such that several of the proteins involved in the pathways that regulate calcium concentrations, including endoplasmic reticulum oxidoreductase $1 \alpha$, arylsulfatase $\mathrm{B}$, nucleolar protein 3, stromal interaction molecule 1 , calcitonin receptor, stromal cell-derived factor 4 , and bcl-2-like protein 4 (Fig. 4). Interestingly, it has been previously shown that celecoxib increases the intracellular concentration of calcium by inhibiting SERCA (Johnson et al., 2002; Wang et al., 2004; Tanaka et al., 2005; Pyrko et al., 2007), and the long-term leakage of calcium from the endoplasmic reticulum acts as a potent stimulant of ER stress, which finally leads to cell death and exerts its effect on cancer (Kim et al., 2007; Pyrko et al., 2007).

Several members of the Rab family are obviously expressed in various cancer tissues, and dysregulation of Rab expression could be tumorigenic or tumor-suppressive (Chia and Tang, 2009). The Rab family plays an essential role in multiple aspects of membrane-trafficking control. Therefore, vesicle transport regulators play crucial roles in the mediation of cancer cell biology, including uncontrolled cell growth, invasion, and metastasis. The Rabs like other members of the Ras superfamily function as molecular switches through changes in their guanine nucleotide-binding status between the active GTP-bound and inactive GDP-bound forms. In its active GTP-bound form, Rabs could mediate vesicular transport by allowing transport carriers or vesicles to engage specific effectors, such as motor proteins and tethering factors as well as vesicle fusion with the engagement of soluble $N$-ethylmaleimide-sensitive factor (Zhao et al., 2007) attachment receptor (Hong, 2005; Ungermann and Langosch, 2005) proteins. Vesicle delivery and dynamics are critical for regulating cell behavior associated with cell migration/invasion and tumorigenesis. Cooperation between Rabs and effectors in mediating vesicle movement pathways has significant influence on tumor progression and malignancy. Therefore, it raises the possibility that targeting a particular trafficking system may provide a new approach to cancer treatment (Tzeng and Wang, 2016). As shown in this study, celecoxib-targeted proteins (i.e., RAB2A, RAB10, and RAB11B) are notably involved in Rab protein signal transduction. As shown in Fig. 4B, TPP-identified proteins are enriched in GDP binding, GTPase activity, and protein phosphatase inhibitor activity that change the GTPases and, as a result, are involved in mechanisms associated with cancer. Therefore, it seems that studying the effect of celecoxib on cancer models by TPP provides more supporting evidence.

Neurodegenerative diseases are also assigned to TPPidentified targets of celecoxib as an anti-inflammatory drug. Recent studies demonstrated that neuronal inflammation is a vital trigger of neurologic diseases (Terzi et al., 2018), and it exacerbates disorders, including Alzheimer, Parkinson, and Huntington diseases as well as amyotrophic lateral sclerosis and multiple sclerosis (Akiyama et al., 2000; Hirsch et al., 2003; McGeer and McGeer, 2004; Eikelenboom and Van Gool, 2004). In the present study, some of the mentioned neurodegenerative disorders were enriched based on phenotypicbased biologic annotations, such as schizophrenia and depression. Twelve of 44 TPP-identified celecoxib targets are involved in Alzheimer disease metabolism, suggesting a high possibility of celecoxib involvement in the mechanisms of this neurodegenerative disease. Notably, inflammation of the nervous system is observed in these disorders, and it is accompanied by an increase in inflammatory cytokines (Philips and Robberecht, 2011; Agius, 2012; Morales et al., 2015). We also illustrated that celecoxib could be beneficial in treating the diseases mentioned above that are associated with inflammation by affecting the biosynthesis pathway of prostaglandins by the involvement of four identified proteins (i.e., dynactin subunit 1 , PSIP1, bcl-2-like protein 4, and AMPH).

Finally, we describe the importance of PTMs for the thermal stability of proteins. We show that multiple PTMs are involved in the protein thermostability. For example, acetylation, which significantly affects the life span of intracellular proteins by avoiding intracellular proteases degradation, is enriched in all TPP-identified proteins (Zhou et al., 2016; Lahusen et al., 2018). Citrullination is the specific PTM identified in celecoxib-treated sample (see Fig. 5). It is related to the change of arginine to citrulline, which strongly affects the structure and function of proteins in both physiologic and pathologic processes, such as apoptosis, multiple sclerosis, and Alzheimer disease (György et al., 2006; Acharya et al., 


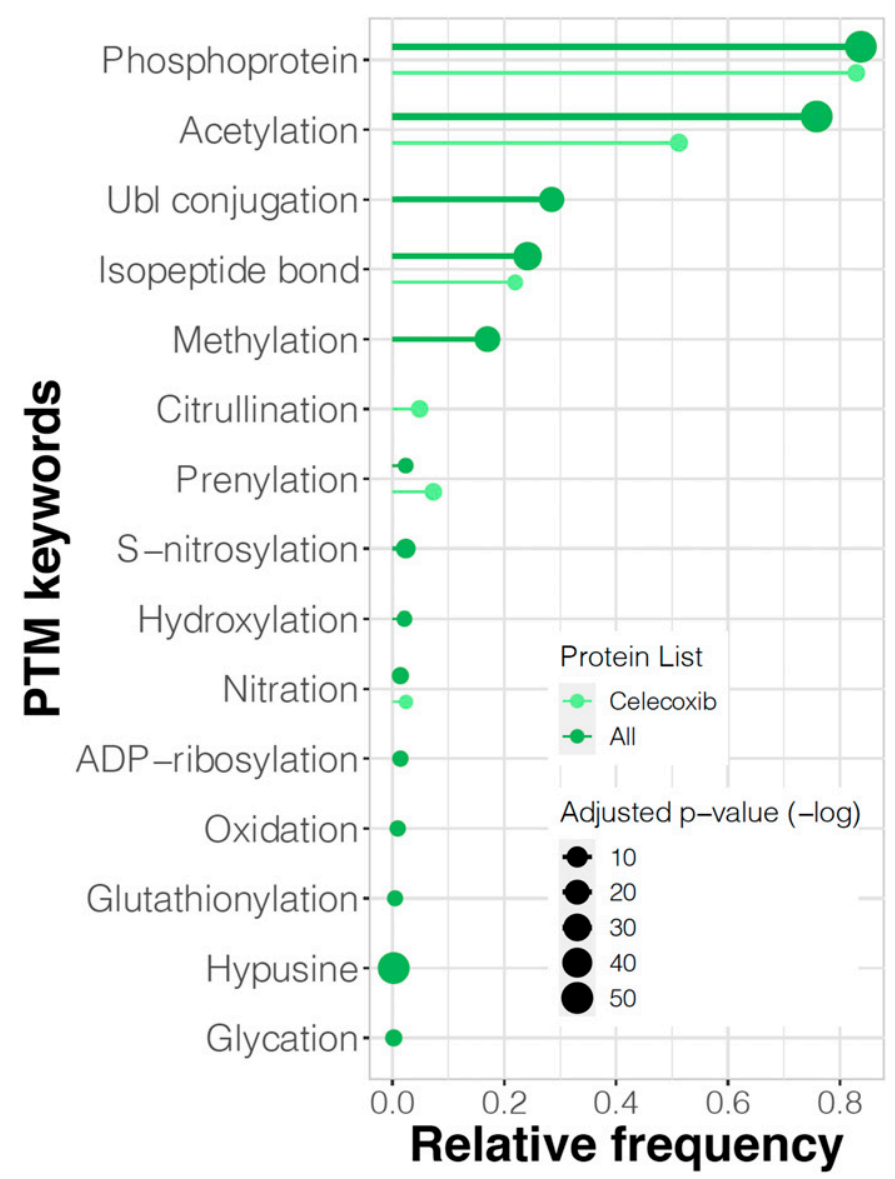

Fig. 5. Enriched PTMs in celecoxib-treated and untreated samples. The PTMs of all identified proteins in our experiment and celecoxib targets were shown by two different colors. The size of the points was adjusted to reflect the avg. of adjusted $P$ values $(-\log 10)$ calculated based on hypergeometric test. UBL, Ubiquitin.

2012; Piran et al., 2020). Interestingly, an important diagnostic tool in the painful inflammatory disease, such as rheumatoid arthritis, is to use anti-cyclic citrullinated peptide antibodies that detect citrullination levels of the patients, and NSAIDs, including celecoxib, are usually prescribed for those patients (Gilliam et al., 2013; Kwiatkowska et al., 2017). Our findings highlight the role of citrullinated proteins as a target of celecoxib.

Although phenotypic-based screens have become increasingly popular in drug discovery, the major challenge of this approach is the mechanistic deconvolution of the putative drug action during screening. The promising TPP approach has been introduced and expanded to tackle such challenges. In the present study, targets of celecoxib within rat hippocampus were characterized using TPP as a high-throughput target discovery approach.

We show that celecoxib plays an effector role in several signaling pathways and biologic processes, which can be linked to various diseases, such as neurodegenerative disorders and cancer. Therefore, in addition to inhibiting COX2, we illustrate that celecoxib might also modify other pathways. Our findings support the pharmaceutical reports related to the repurposing of celecoxib for cancer and neurodegenerative disorders (Chuang et al., 2008; Goldstein et al., 2009; Assefnia et al., 2014). It seems that celecoxib is potentially beneficial for treating cancer by inhibiting SERCA and increasing the intracellular concentration of calcium, which causes ER stress along with cell death. This is another proposed mechanism affecting the trafficking system since transport regulators play essential roles in the mediation of cancer cell biology and especially circulating tumor cells. We found a significant effect of this medicine on proteins involved in the trafficking system of cells.

On the other hand, neuronal inflammation is a major culprit of neurodegenerative diseases, wherein proteins were significantly enriched in the present study. Inflammation in CNS starts by stimulation of astrocytes, and it continues with entering environmental immune cells to the brain. This process causes overproduction of cytokines, nitric oxide, active oxygen species, and prostaglandins and eventually damages and causes death of neurons (Philips and Robberecht, 2011; Nam et al., 2015; Wang et al., 2017; Terzi et al., 2018). Our findings support the idea of using celecoxib for neuronal inflammation because of the explored association of celecoxib targets and the inflammation.

To conclude, we identified several novel celecoxib protein targets using TPP, which could be of interest in modifying several pathways in CNS. Our findings provide new molecular evidence for celecoxib to be used as an add-on therapy in neurodegenerative disorders and cancer. However, more preclinical and paraclinical evidence is required to suggest the true drug-repurposing potential of celecoxib. In general, the potential drug targets can be corroborated by functional studies. Our findings can be considered in different pathophysiological conditions, such as animal models with neurodegenerative disease or cancer with high COX protein family expression and other inflammatory proteins. In the case of providing enough amount of purified protein target, the kinetics and affinities of the drug-target interactions can also be evaluated using various biophysical methods, such as isothermal titration calorimetry and surface plasmon resonance. All told, additional supporting evidence using the possible protein-specific strategies, such as antibody-based and activity-based assays, can support the rationale of celecoxib repositioning.

\section{Acknowledgments}

The authors also acknowledge Dr. Rozbeh Jafari and Dr. Farnaz Barneh for helpful comments.

\section{Authorship Contributions}

Participated in research design: Baumann, Jafari, Tang.

Conducted experiments: Gholizadeh, Karbalaei, Soliymani.

Contributed new reagents or analytic tools: Khaleghian, Salimi, Gilany, Tanoli, Rezadoost, Baumann.

Performed data analysis: Gholizadeh, Soliymani, Rezadoost, Jafari.

Wrote or contributed to the writing of the manuscript: Gholizadeh, Baumann, Jafari, Tang.

\section{References}

Acharya NK, Nagele EP, Han M, Coretti NJ, DeMarshall C, Kosciuk MC, Boulos PA, and Nagele RG (2012) Neuronal PAD4 expression and protein citrullination: possible role in production of autoantibodies associated with neurodegenerative disease. J Autoimmun 38:369-380.

Aebersold R and Mann M (2016) Mass-spectrometric exploration of proteome structure and function. Nature 537:347-355.

Agius LM (2012) Neuroinflammation as the proximate cause of signature pathogenic pattern progression in amyotrophic lateral sclerosis, AIDS, and multiple sclerosis. Pathol Res Int 2012:169270. 
Akiyama H, Barger S, Barnum S, Bradt B, Bauer J, Cole GM, Cooper NR, Eikelenboom P, Emmerling M, Fiebich BL, et al. (2000) Inflammation and Alzheimer's disease. Neurobiol Aging 21:383-421.

Asial I, Cheng YX, Engman H, Dollhopf M, Wu B, Nordlund P, and Cornvik T (2013) Engineering protein thermostability using a generic activity-independent biophysical screen inside the cell. Nat Commun 4:2901.

Assefnia S, Dakshanamurthy S, Guidry Auvil JM, Hampel C, Anastasiadis PZ, Kallakury B, Uren A, Foley DW, Brown ML, Shapiro L, et al. (2014) Cadherin-11 in poor prognosis malignancies and rheumatoid arthritis: common target, common therapies. Oncotarget 5:1458-1474.

Atukorala I and Hunter DJ (2013) Valdecoxib: the rise and fall of a COX-2 inhibitor. Expert Opin Pharmacother 14:1077-1086.

Becher I, Werner T, Doce C, Zaal EA, Tögel I, Khan CA, Rueger A, Muelbaier M, Salzer E, Berkers CR, et al. (2016) Thermal profiling reveals phenylalanine hydroxylase as an off-target of panobinostat. Nat Chem Biol 12 : 908-910.

Bento AP, Gaulton A, Hersey A, Bellis LJ, Chambers J, Davies M, Krüger FA, Light Y, Mak L, McGlinchey S, et al. (2014) The ChEMBL bioactivity database: an update. Nucleic Acids Res 42:D1083-D1090.

Chen EY, Tan CM, Kou Y, Duan Q, Wang Z, Meirelles GV, Clark NR, and Ma'ayan A (2013) Enrichr: interactive and collaborative HTML5 gene list enrichment analysis tool. BMC Bioinformatics 14:128

Chia WJ and Tang BL (2009) Emerging roles for Rab family GTPases in human cancer. Biochim Biophys Acta 1795:110-116.

Chuang HC, Kardosh A, Gaffney KJ, Petasis NA, and Schönthal AH (2008) COX-2 inhibition is neither necessary nor sufficient for celecoxib to suppress tumor cell proliferation and focus formation in vitro. Mol Cancer 7:38.

Dannenberg AJ and Subbaramaiah K (2003) Targeting cyclooxygenase-2 in human neoplasia: rationale and promise. Cancer Cell 4:431-436.

Dembo G, Park SB, and Kharasch ED (2005) Central nervous system concentrations of cyclooxygenase-2 inhibitors in humans. Anesthesiology 102:409-415.

Eikelenboom P and van Gool WA (2004) Neuroinflammatory perspectives on the two faces of Alzheimer's disease. J Neural Transm (Vienna) 111:281-294.

Eppig JT, Smith CL, Blake JA, Ringwald M, Kadin JA, Richardson JE, and Bult CJ (2017) Mouse Genome Informatics (MGI): resources for mining mouse genetic, genomic, and biological data in support of primary and translational research. Methods Mol Biol 1488:47-73.

Fond G, Hamdani N, Kapczinski F, Boukouaci W, Drancourt N, Dargel A, Oliveira J, Le Guen E, Marlinge E, Tamouza R, et al. (2014) Effectiveness and tolerance of anti-inflammatory drugs' add-on therapy in major mental disorders: a systematic qualitative review. Acta Psychiatr Scand 129:163-179.

Franken H, Mathieson T, Childs D, Sweetman GM, Werner T, Tögel I, Doce C, Gade S, Bantscheff M, Drewes G, et al. (2015) Thermal proteome profiling for unbiased identification of direct and indirect drug targets using multiplexed quantitative mass spectrometry. Nat Protoc 10:1567-1593.

Gagliano Taliun SA, VandeHaar P, Boughton AP, Welch RP, Taliun D, Schmidt EM, Zhou W, Nielsen JB, Willer CJ, Lee S, et al. (2020) Exploring and visualizing largescale genetic associations by using PheWeb. Nat Genet 52:550-552.

Gaudet P, Livstone MS, Lewis SE, and Thomas PD (2011) Phylogenetic-based propagation of functional annotations within the Gene Ontology consortium. Brief Bioinform 12:449-462.

Gilliam BE, Chauhan AK, and Moore TL (2013) Evaluation of anti-citrullinated type II collagen and anti-citrullinated vimentin antibodies in patients with juvenile idiopathic arthritis. Pediatr Rheumatol Online J 11:31

Goldstein BI, Kemp DE, Soczynska JK, and McIntyre RS (2009) Inflammation and the phenomenology, pathophysiology, comorbidity, and treatment of bipolar disorder: a systematic review of the literature. J Clin Psychiatry 70:1078-1090.

Goncalves MB, Williams EJ, Yip P, Yáñez-Muñoz RJ, Williams G, and Doherty P (2010) The COX-2 inhibitors, meloxicam and nimesulide, suppress neurogenesis in the adult mouse brain. Br J Pharmacol 159:1118-1125.

Grösch S, Maier TJ, Schiffmann S, and Geisslinger G (2006) Cyclooxygenase-2 (COX2)-independent anticarcinogenic effects of selective COX-2 inhibitors. J Natl Cancer Inst 98:736-747.

Guo M, Xu Y, and Gruebele M (2012) Temperature dependence of protein folding kinetics in living cells. Proc Natl Acad Sci USA 109:17863-17867.

György B, Tóth E, Tarcsa E, Falus A, and Buzás EI (2006) Citrullination: a posttranslational modification in health and disease. Int $J$ Biochem Cell Biol 38 : 1662-1677.

Haas AK, Yoshimura S, Stephens DJ, Preisinger C, Fuchs E, and Barr FA (2007) Analysis of GTPase-activating proteins: Rab1 and Rab43 are key Rabs required to maintain a functional Golgi complex in human cells. J Cell Sci 120:2997-3010.

Hecker N, Ahmed J, von Eichborn J, Dunkel M, Macha K, Eckert A, Gilson MK, Bourne PE, and Preissner R (2012) SuperTarget goes quantitative: update on drugtarget interactions. Nucleic Acids Res 40:D1113-D1117.

Hirsch EC, Breidert T, Rousselet E, Hunot S, Hartmann A, and Michel PP (2003) The role of glial reaction and inflammation in Parkinson's disease. Ann N Y Acad Sci 991:214-228.

Hong W (2005) SNAREs and traffic. Biochimica et Biophysica Acta (BBA)-. Mol Cell Res 1744:120-144.

Jafari M and Ansari-Pour N (2019) Why, when and how to adjust your P values? Cell J 20:604-607.

Jafari M, Mirzaie M, Sadeghi M, Marashi S-A, and Rezaei-Tavirani M (2013) Exploring biological processes involved in embryonic stem cell differentiation by analyzing proteomic data. Biochim Biophys Acta 1834:1063-1069.

Jafari R, Almqvist H, Axelsson H, Ignatushchenko M, Lundbäck T, Nordlund P, and Martinez Molina D (2014) The cellular thermal shift assay for evaluating drug target interactions in cells. Nat Protoc 9:2100-2122.

Jarzab A, Kurzawa N, Hopf T, Moerch M, Zecha J, Leijten N, Bian Y, Musiol E, Maschberger M, Stoehr G, et al. (2020) Meltome atlas-thermal proteome stability across the tree of life. Nat Methods 17:495-503.
Johnson AJ, Hsu A-L, Lin H-P, Song X, and Chen C-S (2002) The cyclo-oxygenase-2 inhibitor celecoxib perturbs intracellular calcium by inhibiting endoplasmic reticulum Ca2+-ATPases: a plausible link with its anti-tumour effect and cardiovascular risks. Biochem $J$ 366:831-837.

Jones R (2001) Nonsteroidal anti-inflammatory drug prescribing: past, present, and future. Am J Med 110:4S-7S.

Kang KB, Zhu C, Yong SK, Gao Q, and Wong MC (2009) Enhanced sensitivity of celecoxib in human glioblastoma cells: induction of DNA damage leading to p53dependent G1 cell cycle arrest and autophagy. Mol Cancer 8:66.

Kashfi K and Rigas B (2005) Non-COX-2 targets and cancer: expanding the molecular target repertoire of chemoprevention. Biochem Pharmacol 70:969-986.

Kim S-H, Hwang C-I, Juhnn Y-S, Lee J-H, Park W-Y, and Song Y-S (2007) GADD153 mediates celecoxib-induced apoptosis in cervical cancer cells. Carcinogenesis 28 $223-231$

Koehne C-H and Dubois RN(2004) COX-2 inhibition and colorectal cancer. Semin Oncol 31 (Suppl 7):12-21.

Köhler S, Carmody L, Vasilevsky N, Jacobsen JOB, Danis D, Gourdine JP, Gargano M, Harris NL, Matentzoglu N, McMurry JA, et al. (2019) Expansion of the human phenotype ontology (HPO) knowledge base and resources. Nucleic Acids Res 47: D1018-D1027.

Kurganov BI, Rafikova ER, and Dobrov EN (2002) Kinetics of thermal aggregation of tobacco mosaic virus coat protein. Biochemistry (Mosc) 67:525-533.

Kutmon M, Riutta A, Nunes N, Hanspers K, Willighagen EL, Bohler A, Mélius J, Waagmeester A, Sinha SR, Miller R, et al. (2016) WikiPathways: capturing the full diversity of pathway knowledge. Nucleic Acids Res 44:D488-D494.

Kwiatkowska B, Majdan M, Mastalerz-Migas A, Niewada M, Skrzydło-Radomańska B, and Mamcarz A (2017) Status of etoricoxib in the treatment of rheumatic diseases. Expert panel opinion. Reumatologia 55:290-297.

Lahusen TJ, Kim SJ, Miao K, Huang Z, Xu X, and Deng CX (2018) BRCA1 function in the intra-S checkpoint is activated by acetylation via a pCAF/SIRT1 axis. Oncogene 37:2343-2350

Larance M and Lamond AI (2015) Multidimensional proteomics for cell biology. Nat Rev Mol Cell Biol 16:269-280.

Li J, Xu H, West GM, and Jones LH (2016) Label-free technologies for target identification and validation. MedChemComm 7:769-777.

Lomenick B, Jung G, Wohlschlegel JA, and Huang J (2011) Target identification using drug affinity responsive target stability (DARTS). Curr Protoc Chem Biol 3 : $163-180$

Luo M-L, Gong C, Chen C-H, Hu H, Huang P, Zheng M, Yao Y, Wei S, Wulf G, Lieberman J, et al. (2015) The Rab2A GTPase promotes breast cancer stem cells and tumorigenesis via Erk signaling activation. Cell Rep 11:111-124.

Marnett LJ, Rowlinson SW, Goodwin DC, Kalgutkar AS, and Lanzo CA (1999) Arachidonic acid oxygenation by COX-1 and COX-2. Mechanisms of catalysis and inhibition. J Biol Chem 274:22903-22906.

Martinez Molina D, Jafari R, Ignatushchenko M, Seki T, Larsson EA, Dan C, Sreekumar L, Cao Y, and Nordlund P (2013) Monitoring drug target engagement in cells and tissues using the cellular thermal shift assay. Science 341: $84-87$.

Masferrer JL, Leahy KM, Koki AT, Zweifel BS, Settle SL, Woerner BM, Edwards DA, Flickinger AG, Moore RJ, and Seibert K (2000) Antiangiogenic and antitumor activities of cyclooxygenase-2 inhibitors. Cancer Res 60:1306-1311.

Mateus A, Määttä TA, and Savitski MM (2017) Thermal proteome profiling: unbiased assessment of protein state through heat-induced stability changes. Proteome Sci 15:13.

McGeer PL and McGeer EG (2004) Inflammation and neurodegeneration in Parkinson's disease. Parkinsonism Relat Disord 10 (Suppl 1):S3-S7.

Morales I, Guzmán-Martínez L, Cerda-Troncoso C, Farías GA, and Maccioni RB (2015) Neuroinflammation in the pathogenesis of Alzheimer's disease. A rational framework for the search of novel therapeutic approaches. Front Cell Neurosci 8 : 112.

Nam SM, Kim JW, Yoo DY, Choi JH, Kim W, Jung HY, Won M-H, Hwang IK, Seong JK, and Yoon YS (2015) Comparison of pharmacological and genetic inhibition of cyclooxygenase-2: effects on adult neurogenesis in the hippocampal dentate gyrus. $J$ Vet Sci 16:245-251.

Nickchi P, Jafari M, and Kalantari S (2015) PEIMAN 1.0: post-translational modification enrichment, integration and matching ANalysis. Database (Oxford) 2015: bav037.

Onder G, Pellicciotti F, Gambassi G, and Bernabei R (2004) NSAID-related psychiatric adverse events: who is at risk? Drugs 64:2619-2627.

Pace CN and McGrath T (1980) Substrate stabilization of lysozyme to thermal and guanidine hydrochloride denaturation. J Biol Chem 255:3862-3865.

Palasca O, Santos A, Stolte C, Gorodkin J, and Jensen LJ (2018) Tissues 2.0: an integrative web resource on mammalian tissue expression [published correction appears in Database (Oxford) (2018) 2018:bay003]. Database (Oxford) 2018: bay028.

Paulson SK, Vaughn MB, Jessen SM, Lawal Y, Gresk CJ, Yan B, Maziasz TJ, Cook CS, and Karim A (2001) Pharmacokinetics of celecoxib after oral administration in dogs and humans: effect of food and site of absorption. J Pharmacol Exp Ther $\mathbf{2 9 7}$ 638-645.

Pei H, Zhu H, Zeng S, Li Y, Yang H, Shen L, Chen J, Zeng L, Fan J, Li X, et al. (2007) Proteome analysis and tissue microarray for profiling protein markers associated with lymph node metastasis in colorectal cancer. J Proteome Res 6:2495-2501.

Perazella MA and Tray K (2001) Selective cyclooxygenase-2 inhibitors: a pattern of nephrotoxicity similar to traditional nonsteroidal anti-inflammatory drugs. Am I Med 111:64-67.

Petsko GA and Ringe D (2004) Protein structure and function, New Science Press.

Philips T and Robberecht W (2011) Neuroinflammation in amyotrophic lateral sclerosis: role of glial activation in motor neuron disease. Lancet Neurol 10:253-263. Piñero J, Bravo À, Queralt-Rosinach N, Gutiérrez-Sacristán A, Deu-Pons J, Centeno E, García-García J, Sanz F, and Furlong LI (2017) DisGeNET: a comprehensive 
platform integrating information on human disease-associated genes and variants. Nucleic Acids Res 45:D833-D839.

Piran M, Karbalaei R, Piran M, Aldahdooh J, Mirzaie M, Ansari-Pour N, Tang J, and Jafari M (2020) Can we assume the gene expression profile as a proxy for signaling network activity? Biomolecules 10:850.

Pyrko P, Kardosh A, Liu Y-T, Soriano N, Xiong W, Chow RH, Uddin J, Petasis NA, Mircheff AK, Farley RA, et al. (2007) Calcium-activated endoplasmic reticulum stress as a major component of tumor cell death induced by 2,5-dimethyl-celecoxib, a non-coxib analogue of celecoxib. Mol Cancer Ther 6:1262-1275.

Rahme E, Bardou M, Dasgupta K, Toubouti Y, Ghosn J, and Barkun AN (2007) Hospitalization for gastrointestinal bleeding associated with non-steroidal antiinflammatory drugs among elderly patients using low-dose aspirin: a retrospective cohort study. Rheumatology (Oxford) 46:265-272.

Reckzeh ES, Brockmeyer A, Metz M, Waldmann H, and Janning P (2019) Target engagement of small molecules: thermal profiling approaches on different levels. Methods Mol Biol 1888:73-98.

Reinhard FB, Eberhard D, Werner T, Franken H, Childs D, Doce C, Savitski MF, Huber W, Bantscheff M, Savitski MM, et al. (2015) Thermal proteome profiling monitors ligand interactions with cellular membrane proteins. Nat Methods 12: 1129-1131.

Sams-Dodd F (2005) Target-based drug discovery: is something wrong? Drug Discov Today 10:139-147.

Savitski MM, Reinhard FB, Franken H, Werner T, Savitski MF, Eberhard D, Martinez Molina D, Jafari R, Dovega RB, Klaeger S, et al. (2014) Tracking cancer drugs in living cells by thermal profiling of the proteome. Science $\mathbf{3 4 6}$ : 1255784 .

Schenone M, Dančík V, Wagner BK, and Clemons PA (2013) Target identification and mechanism of action in chemical biology and drug discovery. Nat Chem Biol $\mathbf{9}$ : $232-240$.

Schmidt C (2010) GSK/Sirtris compounds dogged by assay artifacts. Nat Biotechnol 28:185-186.

Schönthal AH (2007) Direct non-cyclooxygenase-2 targets of celecoxib and their potential relevance for cancer therapy. Br $J$ Cancer 97:1465-1468.

Scifo E, Szwajda A, Soliymani R, Pezzini F, Bianchi M, Dapkunas A, Dęski J, UusiRauva K, Dadlez M, Gingras A-C, et al. (2015) Proteomic analysis of the palmitoyl protein thioesterase 1 interactome in SH-SY5Y human neuroblastoma cells. J Proteomics 123:42-53.

Skuta C, Popr M, Muller T, Jindrich J, Kahle M, Sedlak D, Svozil D, and Bartunek P (2017) Probes \&Drugs portal: an interactive, open data resource for chemical biology. Nat Methods 14:759-760.

Smith WL, DeWitt DL, and Garavito RM (2000) Cyclooxygenases: structural, cellular, and molecular biology. Annu Rev Biochem 69:145-182.

Strickland EC, Geer MA, Tran DT, Adhikari J, West GM, DeArmond PD, Xu Y, and Fitzgerald MC (2013) Thermodynamic analysis of protein-ligand binding interactions in complex biological mixtures using the stability of proteins from rates of oxidation. Nat Protoc 8:148-161.

Sugawara T, Kano F, and Murata M (2014) Rab2A is a pivotal switch protein that promotes either secretion or ER-associated degradation of (pro)insulin in insulinsecreting cells. Sci Rep 4:6952.

Swinney DC (2013) Phenotypic vs. target-based drug discovery for first-in-class medicines. Clin Pharmacol Ther 93:299-301.

Tanaka K Tomisato W, Hoshino T, Ishihara T, Namba T, Aburaya M, Katsu T, Suzuki K, Tsutsumi S, and Mizushima T (2005) Involvement of intracellular Ca2+ levels in nonsteroidal anti-inflammatory drug-induced apoptosis. J Biol Chem 280: 31059-31067.

Tang J, Tanoli ZU, Ravikumar B, Alam Z, Rebane A, Vähä-Koskela M, Peddinti G, van Adrichem AJ, Wakkinen J, Jaiswal A, et al. (2018) Drug target commons: a community effort to build a consensus knowledge base for drug-target interactions. Cell Chem Biol 25:224-229.e2.

Tanoli Z, Alam Z, Vähä-Koskela M, Ravikumar B, Malyutina A, Jaiswal A, Tang J, Wennerberg K, and Aittokallio T (2018) Drug Target Commons 2.0: a community platform for systematic analysis of drug-target interaction profiles. Database (Oxford) 2018:1-13

Tanoli Z, Seemab U, Scherer A, Wennerberg K, Tang J, and Vähä-Koskela M (2020) Exploration of databases and methods supporting drug repurposing: a comprehensive survey. Brief Bioinform DOI: 10.1093/bib/bbaa003 [published ahead of print].

Terzi M, Altun G, Sen S, Kocaman A, Kaplan AA, Yurt KK, and Kaplan S (2018) The use of non-steroidal anti-inflammatory drugs in neurological diseases. $J$ Chem Neuroanat 87:12-24.

Tzeng H-T and Wang Y-C (2016) Rab-mediated vesicle trafficking in cancer. J Biomed Sci 23:70.

Ungermann C and Langosch D (2005) Functions of SNAREs in intracellular membrane fusion and lipid bilayer mixing. J Cell Sci 118:3819-3828.

Usman MG, Rafii M, Ismail M, Malek M, Latif MA, and Oladosu Y (2014) Heat shock proteins: functions and response against heat stress in plants. Int $J$ Sci Technol Res 3:204-218.

Vedadi M, Niesen FH, Allali-Hassani A, Fedorov OY, Finerty PJ Jr, Wasney GA, Yeung R, Arrowsmith C, Ball LJ, Berglund H, et al. (2006) Chemical screening methods to identify ligands that promote protein stability, protein crystallization, and structure determination. Proc Natl Acad Sci USA 103:15835-1c840.

Wang J-L, Lin K-L, Chen J-S, Lu Y-C, Jiann B-P, Chang H-T, Hsu S-S, Chen W-C, Huang J-K, Ho C-M, et al. (2004) Effect of celecoxib on Ca2+ movement and cell proliferation in human osteoblasts. Biochem Pharmacol 67:1123-1130.

Wang R, Tian S, Yang X, Liu J, Wang Y, and Sun K (2017) Celecoxib-induced inhibition of neurogenesis in fetal frontal cortex is attenuated by curcumin via Wnt $\beta$-catenin pathway. Life Sci 185:95-102.

West GM, Tang L, and Fitzgerald MC (2008) Thermodynamic analysis of protein stability and ligand binding using a chemical modification- and mass spectrometrybased strategy. Anal Chem 80:4175-4185.

West GM, Tucker CL, Xu T, Park SK, Han X, Yates JR III, and Fitzgerald MC (2010) Quantitative proteomics approach for identifying protein-drug interactions in complex mixtures using protein stability measurements. Proc Natl Acad Sci USA 107:9078-9082.

Wishart DS, Feunang YD, Guo AC, Lo EJ, Marcu A, Grant JR, Sajed T, Johnson D, Li C, Sayeeda Z, et al. (2018) DrugBank 5.0: a major update to the DrugBank database for 2018. Nucleic Acids Res 46 (D1):D1074-D1082.

Wiśniewski JR, Zougman A, Nagaraj N, and Mann M (2009) Universal sample preparation method for proteome analysis. Nat Methods 6:359-362.

Wongrakpanich S, Wongrakpanich A, Melhado K, and Rangaswami J (2018) A comprehensive review of non-steroidal anti-inflammatory drug use in the elderly. Aging Dis 9:143-150.

Yaksh TL, Dirig DM, Conway CM, Svensson C, Luo ZD, and Isakson PC (2001) The acute antihyperalgesic action of nonsteroidal, anti-inflammatory drugs and release of spinal prostaglandin E2 is mediated by the inhibition of constitutive spinal cyclooxygenase-2 (COX-2) but not COX-1. J Neurosci 21:5847-5853.

Zagidullin B, Aldahdooh J, Zheng S, Wang W, Wang Y, Saad J, Malyutina A, Jafari M, Tanoli Z, Pessia A, et al. (2019) DrugComb: an integrative cancer drug combination data portal. Nucleic Acids Res 47:W43-W51.

Zhao C, Slevin JT, and Whiteheart SW (2007) Cellular functions of NSF: not just SNAPs and SNAREs. FEBS Lett 581:2140-2149.

Zhou Y, Wu C, Sheng Q, Jiang C, Chen Q, Lv Z, Yao J, and Nie Z (2016) Lysine acetylation stabilizes SP2 protein in the silkworm Bombyx mori. J Insect Physiol 91-92:56-62.

Address correspondence to: Mohieddin Jafari, Research Program in Systems Oncology, Faculty of Medicine, University of Helsinki, 00290 Helsinki, Finland. E-mail: mohieddin.jafari@helsinki.fi; or Jing Tang, Research Program in Systems Oncology, Faculty of Medicine, University of Helsinki, 00290 Helsinki, Finland. E-mail: jing.tang@helsinki.fi 